\title{
WHY CANADIANS GIVE TO CHARITY: AN EXTENDED THEORY OF PLANNED BEHAVIOUR MODEL
}

\begin{abstract}
The purpose of this paper is to test an expanded model of charitable giving based on the Theory of Planned Behaviour. The novelty of this research resides in disaggregating the overall attitude a donor may hold into three different attitudes: toward a charity, toward helping, and toward donation. An online survey was conducted among Canadian, resulting in a sample of 202 current donors. By using a hierarchical multiple regression, results show that overall, the extended TPB model proposed in this study is better than those found in the extant research in predicting the intention to donate. The strongest influences on the intention to donate were past behaviour, moral norms, and perceived behavioural control. Subjective norms and attitude toward charitable organisation were found to be nonsignificant predictors. Managerial implications are presented at the end of the paper.
\end{abstract}

KEYWORDS: charitable giving, donor behaviour, theory of planned behaviour, Canada

\subsection{Introduction}

The trends in charitable giving in Canada show that charitable donations are on the decline as fewer individual Canadians are donating to charities than in the past (Turcotte 2015). Somewhat similarly, the United States and the United Kingdom show static giving rates in terms of percentage of income, where most individuals are giving very small sums, amid low donor retention rates, and a generational divide in giving trends between the generous but aging baby boomers and the stingy and aloof millennials (Sargeant 2014). The challenges faced in fundraising by charities are amplified by an increase in demand for their social services by the public, growing competition for grants and other forms of financial support, as well as reduced funding from governments who are looking to the not-for-profit and private sectors to fill the gap from a reduction in government-sponsored support services. Therefore, to increase marketing and fundraising efficacy, the need to improve the targeting of appropriate charitable donors as well as improved quality of communications by non-profit marketers remains critical (Sargeant, 2014).

The theory of planned behaviour (TPB) has been successfully applied to the charitable giving context to help in predicting the intention to donate to charity. However, extant studies measure attitude as a unidimensional construct 
when there is strong theoretical and practical support that implies it should be multidimensional. This paper will attempt to fill this gap by exploring the intention to donate by extending the theory of planned behaviour to include three dimensions of attitude by surveying Canadian donors and analysing the data with hierarchical multiple regression.

\subsection{Background}

The TPB (Ajzen 1991) contends that intentions are the most direct and closest predictor of actual behaviour. According to the TPB, intentions are influenced by the attitude toward the behaviour, subjective norms (perception of others' reaction to their engaging in the behaviour) and perceived behavioural control (PBC; the ability to perform the behaviour). Furthermore, Ajzen (1991) put forth that, after the examination of traditional TPB variables, the TPB can allow additional predictors if these additional predictors can capture a significant proportion of the variance in intention. The TPB literature has expanded to include some additional constructs: moral norms and past behaviour (Conner and Armitage 1998).

Specifically, the TPB has been used to predict prospective donors' intentions in a variety of prosocial activities, such as volunteering (e.g. Okun and Sloane 2002), blood donation (e.g. Veldhuizen, Ferguson, de Kort, Donders, and Atsma 2011), organ donation (e.g. Hyde and White 2009), and bone marrow donation (Bagozzi, Lee, and Van Loo 2001). However, to date only a relatively small number of studies have examined the TPB in the charitable giving context (e.g., Webb, Green, and Brashear 2000; Smith and McSweeney 2007; van der Linden 2011; Kashif and De Run 2015; Kashif, Sarifuddin, and Hassan 2015).

\subsection{Theory of Planned Behaviour and Charitable Giving}

Webb et al. (2000) were amongst the first to adapt the TPB specifically to charitable giving. They investigated the attitudinal construct and analysed it from the perspective of charitable organisations. Central to their conceptualisation was the argument by Fishbein and Ajzen (1975) that asserts that it is possible to hold multiple attitudes towards a behaviour and that there is a conceptual difference between attitude toward the act and attitude toward the object. For Webb, et al. (2000), in the context of charitable giving, this represents the attitude toward helping others and the attitude toward the charity. While previous attempts to measure attitude towards charitable 
giving used a single-measure construct, Webb et al. (2000) posit that attitude toward helping others and attitude toward charitable organisations are "distinct but related determinants of donation behaviour" (pg. 300).

They successfully developed and validated two separate measures: a four-item measure of Attitude toward Helping Others (Cronbach's alpha $=.79)$ and a five-item measure of Attitude toward Charitable Organizations (Cronbach's alpha $=.81)($ Webb et al. 2000). Webb, et al.'s (2000) measures have been used to study charitable donation intention (Ranganathan and Henley 2008), the impact of donation amount on the willingness to pay for cause-related marketing (Koschate-Fischer, Stefan, and Hoyer 2012), explaining volunteer's pro-social attitudes (Briggs, Peterson, and Gregory 2010), and the effects of charity reputation on charitable giving (Meijer 2009).

What Webb et al. (2000) fail to account for is the attitude towards the way through which help can be provided to charitable organisations which include financial donations, volunteering, and social purchasing to name but a few (Peloza and Hassay 2007). Studies have shown that these types of charity helping behaviours are unique and thus should not be treated as equivalent (Drollinger 2010). Smith and McSweeney (2007) develop a unidimensional, eight-item, semantic differential scale to assess Attitude toward Donation. This scale was assessed and showed a Cronbach's alpha of .93 (Smith and McSweeney 2007) indicating an excellent internal consistency.

Focused specifically on financial donations, Smith and McSweeney (2007) used hierarchical regression analysis to assess the predictors of intentions to donate by sampling 227 community members in Australia. The results of their study revealed that the TPB components of attitude toward donation, subjective norms, and PBC significantly predicted intentions to donate $\left(R_{\text {adjusted }}^{2}=0.67\right)$, supporting the applicability of original TPB model to charitable giving (Smith and McSweeney 2007). Their extended model provided support for the inclusion of a number of new constructs; in particular they found support for the inclusion of additional normative constructs, principally moral norms, and past behaviour as they significantly increased the model fit, increasing the $R_{\text {adjusted }}^{2}$ from the traditional TPB of 0.43 to an $R_{\text {adjusted }}^{2}$ of 0.67 for their revised model (Smith and McSweeney 2007).

van der Linden (2011) builds on the work of Smith and McSweeney (2007) by questioning the predictive validity of social norms in studying the intention to donate to charity. He hypothesises that moral norms are the main driver of behavioural intention and not subjective norms. Results of that study confirmed the hypothesis. However, it has been observed that to measure attitude, van der Linden (2011) chose only three of the eight scale items developed by 
Smith and McSweeney (2007) and did not examine any other dimensions of attitude. Nevertheless, the van der Linden model is more parsimonious than the Smith and McSweeney model while accounting for $68 \%$ of the variance in studying intention to donate to charity.

The Smith and McSweeney (2007) model has also been supported by Kashif and De Run (2015) in their study of intention to donate to charity in Pakistan. The survey-based questionnaire used by Kashif and De Run (2015) was identical to that of Smith and McSweeney (2007). The results revealed significant relationship of all construct in the extended TPB model, explaining $63 \%$ of the behaviour intentions among donors.

However, the approach of measuring attitude to charitable giving as a unidimensional construct as exhibited in the extant literature is problematic. In general, MacKenzie (2003) argues that the incorrect definition of a construct can undermine construct validity, statistical conclusion validity, and internal validity. With respect to the attitude construct specifically, Bagozzi and Burnkrant (1979) were among the first to compare the measurement of the attitude construct as either a multidimensional or unidimensional construct. They found that convergent and nomological validity were found for a multidimensional conceptualization of attitude but not supported for a unidimensional one (Bagozzi and Burnkrant, 1979). They surmised that the failure to find a direct relationship between attitude and behavior may be due incorrect specification and measurement of attitude as a unidimensional construct and that proper assessment of the attitude construct required simultaneous measurement and use of each of the multidimensional components (Bagozzi and Burnkrant, 1979).

While limited to a handful of studies, a literature review of the TPB in charitable giving accomplishes two important things. First, there is overall support for the use of the TPB as a framework to study donor behaviour. Second, while the theoretical support exists to allow individuals to hold multiple attitudes and that the charitable giving literature has put forward these measures of attitude, they have never been used in an empirical TPB study of the intention to donate.

\subsection{Attitudes}

In the marketing literature, attitudes can be defined as "relatively enduring evaluations of objects, issues or persons" (Petty, Unnava, \& Strathman, 1991:p.242, as cited in Webb, et al., 2000). Fishbein and Ajzen (1975) suggest attitude towards a behaviour is predicted by two beliefs about the behaviour: beliefs about the likely outcomes of the 
behaviour and the evaluations of these outcomes. It is also possible to hold multiple attitudes about a single behaviour. According to Ajzen (2001), depending on the context, an individual can simultaneously have multiple and conflicting attitudes without any cognitive disagreement. Together, these beliefs produce a favourable or unfavourable attitude towards the behaviour. In applying the TPB constructs to the charitable giving context, the three attitudes towards charitable giving can be described as follows and lead to the first set of hypotheses:

- H1: Attitude towards Donation will positively influence the Intention to Donate

- H2: Attitude towards Helping Others will positively influence the Intention to Donate

- H3: Attitude towards Charitable Organizations will positively influence the Intention to Donate

\subsection{Perceived Behavioural Control}

Perceived behavioural control is defined as "people's perception of the ease or difficulty of performing the behaviour of interest" (Ajzen, 1991, p.193). There are two separate groups of factors which can influence the perceived behavioural control - internal and external. Internal control factors are related to the individual such as personal skill, ability, and information. External control factors lay outside the individual in the environment and may include such things as dependence on others, barriers, or resources (Ajzen, 1985). For example, a donor may wish to make a financial contribution online but not know the website address. Thus, the prospective donor lacks the sufficient information to give and cannot do so based on an internal control factor. Similarly, a person may know the website address and may be willing to donate online, but, being without an Internet connection, a credit card, or the available funds, is unable to do so due to an external control factor. A donor must determine if they have "the necessary resources and opportunities to perform the behaviour successfully, weighted by the perceived power of each factor to facilitate or inhibit behaviour" (Conner \& Armitage, 1998, p. 1432). Accordingly, we hypothesize:

- H4: Perceived Behavioural Control will positively influence the Intention to Donate

\subsection{Subjective and Moral Norms}

Subjective norms are the perceived social reaction to engaging or not engaging in a given behaviour. There are two components to Fishbein and Ajzen's (1975) subjective norms, normative beliefs and motivation to comply. Normative beliefs are beliefs held by an individual about what other people, important to the individual, believe 
about whether one should or should not engage in the behaviour. The importance of the belief about what others want is influenced by the desire to meet those preferences. For example, prospective charitable donors may perceive that their partner would not approve of them making a large charitable donation, and if motivated to seek their approval or avoid disapproval, a negative subjective norm towards making a donation may be generated. However, if all their friends are also making a donation, a positive subjective norm towards a donation may be generated.

Subjective norms have consistently been shown to be the weakest predictor of intentions and a move to include other norms in the TPB to increase validity has led to the introduction of moral norms (Rivis, Sheeran, \& Armitage, 2009). In a meta-analysis of the addition of moral norms to the TPB, Rivis et al. (2009) find that the addition of moral norms to the model leads to a significant increase in the variance explained in donor intentions.

Moral norms, referred to as moral obligations or personal norms, are theoretically different from subjective norms and reveals feelings about personal responsibility or duty to perform a given behaviour because it is just inherently right or wrong regardless of the personal or social consequences (Manstead, 2000). As opposed to subjective norms, which reflect social pressures and expectations, moral norms are personal and internalized (Manstead, 2000). In certain contexts, Ajzen (1991) believes that a measure of moral norms could add predictive power to the model and there is strong empirical evidence to support this particularly for behaviour involving ethical or prosocial behaviours (Manstead, 2000). Beck and Ajzen (1991) first put forward the use of moral norms in the TPB by studying cheating, shoplifting and lying behaviour. As such, we hypothesize that:

- H5: Subjective Norms will positively influence the Intention to Donate

- H6: Moral Norms will positively influence the Intention to Donate

While not included in the original TPB, the role of past behaviour has attracted considerable attention in the study of planned behaviour and been used in numerous extended models. Several studies have examined the role of past behaviour as an additional predictor of unique variance in intentions and behaviour (e.g. Conner, Warren, Close, \& Sparks, 1999). Some studies have found that past behaviour is the best predictor of future behaviour, stronger than either attitudes or PBC (e.g. Conner, Norman, \& Bell, 2002). In the reviewed studies of TPB in charitable giving, past behaviour has been posited to be an important and independent predictor of behavioural intention to donate (Smith \& McSweeney, 2007; Oosterhof et al., 2009; van der Linden, 2011). There is sufficient theoretical support to 
include past behaviour in a study of the TPB as it may account for a substantial portion of the variance in charitable giving. Therefore, our final hypothesis is:

- H7: Past Behaviour will positively influence the Intention to Donate

\subsection{Purpose of the Study}

The purpose of this study is to test an expanded TPB model in charitable giving by including and examining the multiple attitudes a donor may hold toward different components of the financial donor experience: attitudes towards charitable organizations, attitudes towards helping others, and attitudes towards financial donations. Thus addressing limitations of previous studies which used a unidimensional construct for attitude and the accuracy of their conclusions. We take up the call by Wymer and Alves (2013, p. 66) for "nonprofit scholars to develop appropriate conceptualizations of constructs and valid measures for those constructs" with a focus on refining the use of the attitude toward charitable giving construct in nonprofit marketing. This study will attempt to improve on existing models using a multidimensional conceptualization of attitude to charitable giving, with more specificity about each of the various dimensions, and thus predict a greater amount of the variance in the intention to donate to charity.

\subsection{Method}

In order to test the extended model, an eight-section questionnaire was designed in order to carry out an online survey. All constructs were measured using 7-point, Likert-style questions (see Table 1). The Intention to Donate was measured using Ranganathan and Henley's (2008) 4-item scale. The Attitude toward Helping Others and Attitude toward Charity were measured using Webb, et al.'s (2000) 4-item measures respectively. The Attitude toward Donation was measured using Smith and McSweeney's (2007) 8-item measure. As the extant literature on the TPB in charitable giving was based heavily on Smith and McSweeney (2007), their measures for Moral Norms (4-items), Subjective Norms (3-items), Past Behaviour (5-items), and PBC (5-items) were also used. Participants were told to focus on monetary donations to charity as the method of charitable giving. Some questions asked them to recall their past monetary donations while other questions asked them about what they would do in the future.

\section{Table 1 - Summary of Constructs}




\begin{tabular}{|c|c|}
\hline Construct & $\alpha$ \\
\hline Intention to Donate (Strongly Disagree (1) to Strongly Agree (7)) (INTDON) & .964 \\
\hline \multicolumn{2}{|l|}{$\begin{array}{l}\text { In the coming year I am planning to donate money to charity. } \\
\text { It is my intention to donate money in the coming year. } \\
\text { It is very likely that I will donate to charity. } \\
\text { I will definitely donate to charity. }\end{array}$} \\
\hline $\begin{array}{l}\text { Attitude towards Helping Others (Strongly Disagree (1) to Strongly Agree (7)) } \\
\text { (ATHO) }\end{array}$ & .893 \\
\hline \multicolumn{2}{|l|}{$\begin{array}{l}\text { People should be willing to help others who are less fortunate. } \\
\text { Helping troubled people with their problems is very important to me. } \\
\text { People should be more charitable towards others in society. } \\
\text { People in need should receive support from others. }\end{array}$} \\
\hline Attitude towards Charity (Strongly Disagree (1) to Strongly Agree (7)) (ATC) & .817 \\
\hline \multicolumn{2}{|l|}{$\begin{array}{l}\text { The money given to charities goes for good causes. } \\
\text { Much of the money donated to charity is wasted. (R) } \\
\text { My image of charitable organization is positive } \\
\text { Charitable organizations have been quite successful in helping the needy. } \\
\text { Charity organizations perform a useful function for society. }\end{array}$} \\
\hline Attitude towards Donation variables $(1$ - lowest, 7 - highest) (ATD) & .970 \\
\hline $\begin{array}{l}\text { My making a monetary donation to charity in the next } 4 \text { weeks would be: } \\
\text { Very unpleasant to Very pleasant } \\
\text { Very useless to Very useful } \\
\text { Very unsatisfying to Very satisfying } \\
\text { Very unfavourable to Very favourable } \\
\text { Very negative to Very positive } \\
\text { Very inconsiderate to Very considerate } \\
\text { Very pointless to Very worthwhile } \\
\text { Very bad to Very good }\end{array}$ & \\
\hline Moral Norms (Strongly Disagree (1) to Strongly Agree (7)) (MORAL) & .869 \\
\hline \multicolumn{2}{|l|}{$\begin{array}{l}\text { I am the kind of person who donates money to charity. } \\
\text { I would feel guilty if I did not donate money to charity. } \\
\text { I believe I have a moral obligation to donate money to charity. } \\
\text { Not donating money to charities goes against my principles. }\end{array}$} \\
\hline Subjective Norms (SUBJ) & .590 \\
\hline \multicolumn{2}{|c|}{$\begin{array}{l}\text { The people closest to me would support my decision to make monetary donations to distan } \\
\text { others. (Strongly Disagree (1) to Strongly Agree (7)) } \\
\text { The people closest to me would disapprove if I donated money to distant others. (Very Unlikely } \\
\text { (1) to Very Likely (7)) (Reverse-scored) } \\
\text { Most people who are important to me think that my donating money to distant others would be: } \\
\text { (Very Undesirable (1) to Very Desirable (7)) }\end{array}$} \\
\hline Past Behaviour $(\mathrm{PB})$ & .898 \\
\hline \multicolumn{2}{|c|}{$\begin{array}{l}\text { I do not donate money to charities (Never true (1) to Always true (7)) (R) } \\
\text { I have not recently donated any money to charity (Never true (1) to Always true (7)) (R) } \\
\text { It is unusual for me to donate money to charities (Strongly disagree (1) to Strongly agree (7)) (R) } \\
\text { I usually donate money to charities (Strongly disagree (1) to Strongly agree (7)) } \\
\text { How often have you recently donate money to charities (Never (1) to Very frequently (7)) }\end{array}$} \\
\hline Perceived Behavioural Control (PBC) & .826 \\
\hline
\end{tabular}


If I wanted to, I could easily donate money to charities in the next month (Strongly disagree (1) to Strongly agree (7))

Overall, how much control do you have over whether you donate money to charities in the next month (No control (1) to Complete control (7))

It is mostly up to me whether I donate money to charities in the next month (Strongly disagree (1) to Strongly agree (7))

I am confident that I will be able to donate money to charities in the next month. (Strongly disagree (1) to Strongly agree (7))

Donating money to charities in the next month is easy for me to do. (Strongly disagree (1) to Strongly agree (7))

(R) - reverse scored

They survey instrument was placed on Survey Monkey and participants were recruited through Survey Monkey Audience. The population surveyed included a diverse group of people from across the Canadian populations who have Internet access. Participants have voluntarily completed various prior Internet surveys and were interested in taking additional ones. While no direct incentives were offered, the online survey provider did offer its participants various types of non-monetary incentives, including a contribution to a charity of the member's choice. The only targeting criterion was that participants must be older than 18 years of age. In total, 249 people responded while 202 people completed the survey resulting in an $81 \%$ completion rate from starting. Respondents came from across Canada including Atlantic Canada (19, 9.55\%), Quebec (41, 20.6\%), Ontario (77, 38.69\%), Prairies (34, 17.09\%), BC $(23,11.56 \%)$, and Northern Canada $(5,2.51 \%)$. Respondents profiles indicated that slightly more females $(57.3 \%)$ than males participated, the majority had at least a 4-year college degree (62.4\%), and an annual income of less than $\$ 100,000 \mathrm{CAD}(85 \%)$. The average time to complete the survey was 11 minutes and 18 seconds. This is well under the targeted maximum of 20 minutes to complete the questionnaire set to avoid potential respondent fatigue or the average attention span of an adult student (Middendorf and Kalish 1996).

To analyse the data, hierarchical multiple regression (HMR) was chosen. In HMR, the independent variables are entered into a regression analysis in a specified order. This is done to examine the specific contribution of each independent variable after controlling for more general variables. In the case of extending the Theory of Planned Behaviour in charitable giving, it allowed for the examination and control of the original TPB variables and the individual contribution of the various dimensions of attitude. HMR, as opposed to structural equation modelling which tests all variables simultaneously, allows for the identification of the added value of each individual variable towards the overall explained variance. Additionally, it will facilitate comparison with existing extended models of 
the theory of planned behaviour in charitable giving as HMR was used by Smith and McSweeney (2007), van der Linden (2011), and Kashif and De Run (2015) in their respective TPB studies in charitable giving.

\subsection{Results}

Before conducting the hierarchical regression analysis, each of the constructs was analysed for consistency and reliability. All the Cronbach alpha coefficients were above 0.81, with the only exception being Subjective Norms ( $\alpha$ $=0.59$ ) thus placing a question mark upon its contribution to the model (see Table 1 for a recap). The results of the analysis is consistent with the extant literature as each of the studies show Subjective Norms with an equally low Cronbach alpha coefficient. All the other constructs seem to show a reasonable level of reliability above the baseline of 0.70 (Nunnally and Bernstein 1994).

The constructs were also tested for face validity, content validity, nomological validity, convergent validity, and external validity in line with many of the best practice recommendations by Wymer and Alves (2013). The construct and items developed here for the charitable giving were reviewed by two independent reviewers and no items seemed out of place. As such, the constructs met the requirements of face validity. Content validity was met after an extensive review of the literature from appropriate areas including a review of the measures previously used, a review of the content by experts, and by pilot testing. Nomological validity is an assessment of whether the appropriate items and constructs have been included in the model and whether any have been neglected. This can be determined based on extant literature related to the model. After review, the constructs proposed offer nomological validity. Convergent validity is the degree to which two or more attempts to measure the same concept through maximally different methods are in agreement (Peter, 1981). The items for each construct were factor analyzed to determine whether all items merit inclusion in the construct. If all items load heavily on the first factor extracted, one can usually conclude that the items are all dimensions of the same underlying factor (Reve, 1979). With respect to the constructs used in the model, all factor loadings are significant thus supporting the convergent validity for the constructs. In order to show external validity in the proposed model, an effort was made to use established constructs which have been applied in both charitable giving and other settings. The constructs from the TPB (attitudes, moral norms, perceived behavioural control, past behaviour) have been used in numerous contexts and in numerous countries including a number of various prosocial and consumer behaviours such as volunteering (Warburton \& Terry, 2000), blood donation (Giles \& Cairns, 1995), dieting (Armitage \& Conner, 1999), and 
recycling (Mannetti, Pierro, \& Livi, 2004). The TPB is also used in the study of charitable giving in a number of countries including The Netherlands, Germany, and the United Kingdom (van der Linden, 2011), Australia (Smith \& McSweeney, 2007; Knowles, et al., 2012), Pakistan (Kashif \& de Run, 2015) Malaysia (Kashif, et al., 2015).

These studies also used the intention to donate as their behavioural intention in question. As all constructs have been used in different settings with different samples, external validity has been demonstrated. Furthermore, examination of the items and constructs for assumptions of normality was conducted using values of skewness and kurtosis and all were found to be in normal ranges.

For the purpose of testing, a hierarchical multiple regression analysis, enter procedure, was used to regress Intention to Donate onto the revised TPB model, where:

$$
I N T D O N=\beta 0+\beta 1 A T D+\beta 2 A T H O+\beta 3 A T C+\beta 4 P B C+\beta 5 S U B J+\beta 6 M O R A L+\beta 7 P A S T+\varepsilon
$$

Note: Intention to Donate (INTDON), Attitude toward Donation (ATD), Attitude toward Helping Others (ATHO), Attitude toward Charity (ATC), Perceived Behavioural Control (PBC), Subjective Norms (SUBJ), Moral Norms (MORAL), Past Behaviour (PAST), Error Term (c)

The constructs' values were computed as the average score for the constructs' individual items (taking the reverse scores into account). Following the methodology used in hierarchical multiple regression for predicting the intention to donate in charitable giving from Smith and McSweeney (2007), van der Linden (2011), and Kashif and De Run (2015), Steps 1 through 3 of the HMR focused on adding the traditional TPB variables. Step 1 added the three 'attitude' variables of Attitude toward Donation, Attitude toward Charity, and Attitude toward Helping Others. Perceived Behavioural Control was added in Step 2 and then the two 'norms' variables of Subjective Norms and Moral Norms were added in Step 3. The final step, Step 4, involved adding Past Behaviour to the regression analysis. Results of this analysis are presented in Table 2. 
Table 2 Results - Hierarchical Multiple Regression on Intention to Donate

\begin{tabular}{llccccc}
\hline Step & Predictor & $\begin{array}{c}\text { R } \\
\text { Squared } \\
\text { Adjusted }\end{array}$ & $\begin{array}{c}\text { R Squared } \\
\text { Change }\end{array}$ & $\begin{array}{c}\text { F- } \\
\text { Value }\end{array}$ & F Change & $\begin{array}{c}\text { Standardized } \\
\text { Beta }(\boldsymbol{\beta})\end{array}$ \\
\hline 1 & $\begin{array}{l}\text { Attitude toward Donation } \\
\text { Attitude toward Helping }\end{array}$ & 0.504 & 0.511 & 67.934 & 67.934 & $0.174^{* * *}$ \\
& $\begin{array}{l}\text { Others } \\
\text { Attitude toward Charity }\end{array}$ & & & & & $0.151^{* * *}$ \\
& $\begin{array}{l}\text { Perceived Behavioural } \\
\text { Control }\end{array}$ & 0.657 & 0.153 & 95.702 & 88.039 & $0.249^{* * *}$ \\
\hline 2 & $\begin{array}{l}\text { Subjective Norms } \\
\text { Moral Norms }\end{array}$ & 0.713 & 0.058 & 83.044 & 20.08 & 0.031 \\
\hline 3 & Past Behaviour & 0.759 & 0.046 & 90.148 & 37.653 & $0.266^{* * *}$ \\
\hline 4 & & & & & & \\
\hline
\end{tabular}

$* \mathrm{p}<0.10$

$* * \mathrm{p}<0.05$

$* * * \mathrm{p}<0.01$

Note: The beta weights reported are the values at the final step

The first group of variables composed by the attitude toward donation, attitude toward helping others and attitude toward charity, which were entered one at a time in the regression, contribute significantly to the explained variance $(\mathrm{R}-$ Square Change $=0.511, \mathrm{~F}(3,195)=67.934)$. Further inspection indicated a significant effect for ATD $\beta=0.174$ and ATHO $\beta=0.151$ while ATC was found to be non-significant in predicting intention to donate. In the second step, the inclusion of PBC added a significant increase in the variance explained (R-Square Change $=0.153 \mathrm{~F}(4$, 194) 95.702$)$. The $\beta$ weight for PBC was $0.249(\mathrm{p}<0.01)$.

The third step consisted in adding SUBJ and MORAL into the hierarchical regression. Results show again an increased in the variance explained $(\mathrm{R}-$ Squared Change $=0.058, \mathrm{~F}(6,192)=83.044)$. Further analysis revealed a significant effect for moral norms only $(\beta=.248, \mathrm{p}<0.01)$. Subjective norms were found to be non-significant in predicting the intention to donate. Therefore, the increase in explained variance can be fully attributed to moral norms. Lastly, PAST was entered and produced a significant increase in the variance explained (R-Square Change $=$ $0.046, \mathrm{~F}(7,191)=90.148)$. The more respondents had donated in the past, the stronger their intention to donate in the future $(\beta=0.266, \mathrm{p}<0.01)$. With all variables in the equation, the revised TPB model accounted for $76 \%$ of the variance in the Intention to Donate (see Figure 1). 
Figure 1- Results of the Extended Theory of Planned Behaviour Model in Charitable Giving

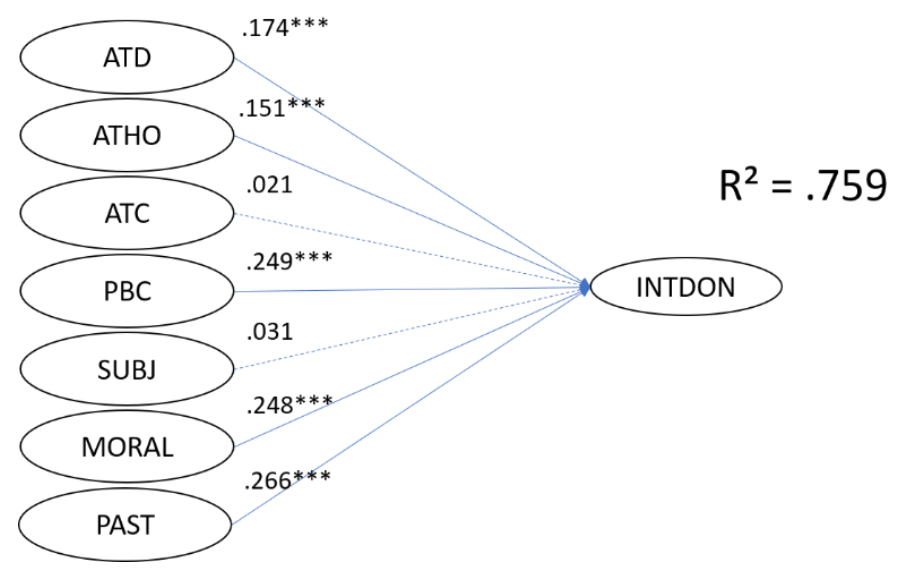

Note: solid line represents significant relationship, dashed line represents non-significant relationship

Note: $* \mathrm{p}<0.10, * * \mathrm{p}<0.05, * * * \mathrm{p}<0.01$

Capturing $76 \%$ of the variance in the Intention to Donate, this model is an excellent fit and significantly better than those models found in the literature (see Table 3). The regression found that Past Behaviour is the strongest predictor of the Intention to Donate with Moral Norms and Perceived Behavioural Control influencing the Intention to Donate by almost as much.

Table 3 - TPB in Charitable Giving Model Comparison

\begin{tabular}{|l|l|l|l|l|}
\hline & $\begin{array}{c}\text { This Study } \\
\text { (Authors' omitted) }\end{array}$ & \multicolumn{1}{|c|}{$\begin{array}{c}\text { Smith and } \\
\text { McSweeney } \\
(2007)\end{array}$} & $\begin{array}{c}\text { Van der Linden } \\
(2011)\end{array}$ & $\begin{array}{c}\text { Kashif and De Run } \\
(2015)\end{array}$ \\
\hline ATD --> INTDON & $0.17^{* * *}$ & $0.11^{*}$ & $0.21^{* * *}$ & $0.26^{* *}$ \\
\hline ATC --> INTDON & 0.02 & Not considered & Not considered & Not considered \\
\hline ATHO --> INTDON & $0.15^{* * *}$ & Not considered & Not considered & Not considered \\
\hline PBC --> INTDON & $0.25^{* * *}$ & $0.24^{* * *}$ & $0.27^{* * *}$ & $0.31^{* *}$ \\
\hline SUBJ --> INTDON & 0.03 & $0.13^{*}$ & -0.16 & $0.27^{* *}$ \\
\hline MORAL--> INTDON & $0.25^{* * *}$ & $0.15^{* * *}$ & $0.51 * * *$ & $0.34^{* *}$ \\
\hline PAST --> INTDON & $0.27 * * *$ & $0.54 * * *$ & $0.49 * * *$ & $0.29 * *$ \\
\hline R $^{2}$ Adjusted & $\mathbf{0 . 7 6}$ & $\mathbf{0 . 6 7}$ & $\mathbf{0 . 6 8}$ & $\mathbf{0 . 6 3}$ \\
\hline
\end{tabular}

$* \mathrm{p}<0.10, * * \mathrm{p}<0.05, * * * \mathrm{p}<0.01$ 


\subsection{Attitude toward Charitable Giving}

Previous studies of the TPB model in charitable giving have used a single measure of attitude based on the work of Smith and McSweeney (2007). This is the first study to examine simultaneously the three types of attitudes previously identified: toward donation, toward charitable organisation, and toward helping others. The results show that both Attitudes toward Donation and Attitudes toward Helping Others are separate, positive, and significant predictors of the Intention to Donate (H1 and $\mathrm{H} 2$ supported), while the Attitude toward Charity is non-significant (H3 not supported). The extant research, as shown in Table 3, found that their single measure of attitude was also significant and positive in predicting the intention to donate (Smith and McSweeney 2007; van der Linden 2011; Kashif and De Run 2015). There was, therefore, agreement about the role of attitude toward donation while the investigation of attitude toward helping others and attitude toward charitable organisations is unique to this study.

\subsection{Perceived Behavioural Control}

The results across all four studies shown in Table 3 were similar with respect to the relationship between PBC and the intention to donate, with Kashif and De Run slightly higher than the others. In all cases, PBC was found to be a positive and significant predictor (H4 supported).

\subsection{Subjective Norms}

The relationship between subjective norms and the intention to donate was found to be non-significant in this study (H5 not supported) and in van der Linden (2011) but was found to be significant in Smith and McSweeney (2007) and Kashif and De Run (2015). van der Linden (2011) explains that his results are not completely out of line with extant research, including Smith and McSweeney (2007), in that previous studies have only found partial evidence to support the predictive validity of subjective norms in prosocial behaviours. van der Linden (2011) also discusses the low-reliability coefficient of the subjective norm index in his study as less than optimal. This is also the case in this study with the Subjective Norm scale having a very low Cronbach's Alpha.

\subsection{Moral Norms}


Moral Norms were always found to be significant and positive predictors of the Intention to Donate (H6 supported). The $\beta$ values do vary a great deal between the samples. For both van der Linden (2011) and Kashif and De Run (2015), moral norms are the strongest predictor of the intention to donate.

\subsection{Past Behaviour}

Across the studies, there is a strong, positive, and significant relationship between Past Behaviour and the Intention to Donate (H7 supported). Furthermore, in both this study and Smith and McSweeney (2007), this relationship is the strongest predictor of the intention to donate.

\subsection{Discussion}

While all four models presented in Table 3 demonstrate acceptable model fit as expressed by the adjusted Rsquared, the results from this study predict $8 \%$ more than any of the existing models with an adjusted R-squared of 0.76. While the models are different in terms of the number of predictors, the adjusted R-squared has been used for just this purpose, the comparison of the explanatory power of different regression models with a different number of predictors. The Kashif and De Run (2015) model predicts the least of the intention to donate (0.63), while the Smith and McSweeney (2007) and van der Linden (2011) have similar R-squared results of 0.67 and 0.68 respectively.

Overall, the extended TPB model proposed in this study found that the strongest influences on the intention to donate were past behaviour, moral norms, and perceived behavioural control. The biggest difference between the three extant studies and the one used here is the disaggregation of the attitude construct.

What these extant studies failed to examine was the distinction between the attitude toward donation (making a financial donation), the attitude toward the intermediary (the charity) and the attitude toward the object (helping the beneficiary). By using the multi-dimensional construct, this study was able to discover the importance of the attitude toward helping others as well as the non-significance of the attitude toward charitable organisations. The use of the multi-dimensional constructs improved results substantially when compared with other TPB in charitable giving studies. Future studies of charitable giving that examine attitude should strongly consider the various dimensions of attitude toward charitable giving.

Moral norms were significantly influential while subjective norms were non-significant. This result has not been consistent across studies and this could be related to the particular nature and culture of the countries sampled. 
Canada, where subjective norms were non-significant, is considered an individualistic country (Hofstede 2001). Conversely, Kashif and De Run (2015) found that subjective norms were a significant, strong and positive predictor of the intention to donate in their sample in Pakistan, which is considered a collectivistic country (Hofstede 2001). The vast majority of studies on subjective norms (perception of others' reaction to their engaging in the behaviour) have taken place in single country settings either in North America or East Asia (Smith 2015). The countries in these areas represent both highly individualistic and highly collectivistic cultures, respectively. Matsumoto, Yoo, and Fontaine (2008) examined the influence of subjective norms across 32 nations and found that individualismcollectivism could explain important differences in the way that subjective norms influence behaviour. Other possible explanations could be related to the idea that charitable giving usually takes place in private or anonymously thereby activating moral norms as opposed to social or subjective norms (van der Linden 2011) or that people tend to underestimate the influence of subjective norms and social pressures on their behaviour (Nolan, Schultz, Cialdini, Goldstein, and Griskevicius 2008).

\subsection{Managerial Implications}

The findings with respect to each of the constructs investigated present a number of managerial implications. The study began examining three different attitudes towards charitable giving: the attitude towards charitable organisations, the attitude towards donations, and the attitude towards helping others. In terms of predicting the intention to donate, both the attitude toward donation and the attitude towards helping others was found to be significant where those who show a more positive attitude towards helping others are more likely to donate. Therefore, a non-profit marketer may consider targeting those who already help others as well as emphasizing the donation and the benefit it creates and less on the organisation.

This study also found that past donation behaviour is the strongest predictor of the intention to donate. This result fits within extant non-profit marketing literature and the service quality literature. The importance of strengthening the link between past behaviour and the intention to donate for non-profit marketers is significant as an increase of $10 \%$ in donor loyalty can results in an improvement of $100 \%$ to $150 \%$ in ROI depending on the nature of the campaign (Sargeant and Woodliffe 2007). Sargeant and Woodliffe (2007) examine repeat and loyal donors and find that they are driven by five factors including perceived service quality, shared beliefs, perceived risk, and the existence of a personal link to the organisation or cause, and trust. 
The implications of the strength of the relationship between perceived behavioural control and the intention to donate are that for non-profits to increase donations they need to make the process of donating as easy and accessible as possible. Sargeant, West, and Jay (2007), in a study of online fundraising effectiveness, found that website accessibility (or making it easy for the donor to offer support) is significantly and positively correlated with both the number of new donors a site can attract as well as with the total value of online donations. The importance of information communication technologies and website design is becoming of paramount importance for the future of charitable giving. This includes the growing importance of social media tools, such as Facebook, Twitter, YouTube, and Instagram to promote giving as well as exploring donations by text message.

Finally, due to the potential influence of individualism-collectivism on the impact of subjective norms upon intention to donate, non-profit marketers need to consider the local culture when appealing for donations.

\subsection{Limitations and Further Research}

It should be acknowledged that the sampling for this study may not be fully representative. Likewise, there is a potential risk of a non-response error, though an effort was made to obtain responses from a wide variety of geographic regions in the targeted country as well as a range of other demographic characteristics. There is also a concern about social desirability bias in studies on charitable giving and other prosocial behaviour due to the sensitive nature of the research. Therefore, in order to improve generalizability and external validity, the hierarchical model for the intention to donate should be tested in other countries and cultures. While the current model has a high $\mathrm{R}^{2}$, following Ajzen's (1991) instructions, future studies could include other extensions of the TPB such as internal ethics and moral intensity (Rex, Lobo, and Leckie, 2015), religiosity (Reitsma, Scheepers, \& Grotenhuis, 2006), and emotional involvement (Bartolini, 2005) if they can add significantly to the explanatory power of the model. Furthermore, as highlighted by Johnstone \& Lindh (2018), millennial consumers (or donors), place considerable value on influencers as motivators, often more so than the product or cause, and therefore it is important to consider the mediating and moderating role of influencers on the intention to donate. Finally, the results of this study should only be applied to monetary donations to charities. For example, the hypotheses could be tested against the intention to donate time (volunteering) or to donate used goods.

\section{References}


Ajzen, I. (1985). From Intention to Actions: A Theory of planned Behavior, In: J. Kuhl, J. Bechmand (Eds.), Action Control: From Cognition to Behavior, Springer, New York.

Ajzen, I. (1991). Theory of planned behavior. Organizational Behavior and Human Decision Processes, 50, 179211.

Ajzen, I. (2001). Nature and operation of attitudes. Annual Review of Psychology, 52(1), 27-58.

Armitage, C. J., \& Conner, M. (1999). Distinguishing Perceptions of Control From Self- Efficacy: Predicting Consumption of a Low-Fat Diet Using the Theory of Planned Behavior. Journal of applied social psychology, 29(1), 72-90.

Bagozzi, R. P., \& Burnkrant, R. E. (1979). Attitude measurement and behavior change: A reconsideration of attitude organization and its relationship to behavior, in NA - Advances in Consumer Research, 6, 295-302

Bagozzi, R. P., Lee, K. H., and Van Loo, M. F. (2001). Decisions to donate bone marrow: The role of attitudes and subjective norms across cultures. Psychology and Health, 16(1), 29-56.

Bartolini, W. F. (2005). Prospective donors' cognitive and emotive processing of charitable gift requests (Doctoral dissertation, Kent State University).

Beck, L., \& Ajzen, I. (1991). Predicting Dishonest Actions Using the Theory of Planned Behaviour. Journal of Research in Personality, 25, 285-301.

Briggs, E., Peterson, M., and Gregory, G. (2010). Toward a better understanding of volunteering for nonprofit organizations: explaining volunteers’ pro-social attitudes. Journal of Macromarketing, 30(1), 61-76.

Conner, M., and Armitage, C. J. (1998). Extending the theory of planned behavior: A review and avenues for further research. Journal of Applied Social Psychology, 28, 1429-1464.

Conner, M., Norman, P., \& Bell, R. (2002). The theory of planned behavior and healthy eating. Health Psychology, 21(2), 194-201.

Conner, M., Warren, R., Close, S., \& Sparks, P. (1999). Alcohol consumption and the theory of planned behavior: An examination of the cognitive mediation of past behavior. Journal of Applied Social Psychology, 29(8), 1676-1704.

Drollinger, T. (2010). A Theoretical Examination of Giving and Volunteering Utilizing Resource Exchange Theory. Journal of Nonprofit and Public Sector Marketing, 22(1), 55-66. 
Fishbein, M., and Ajzen, I. (1975). Belief, attitude, intention, and behavior: An introduction to theory and research. Reading, MA: Addison-Wesley.

Giles, M., and Cairns, E. (1995). Blood donation and Ajzen's theory of planned behaviour: an examination of perceived behavioural control. British Journal of Social Psychology, 34(2), 173-188.

Hofstede, G. (2001). Culture's consequences: Comparing values, behaviors, institutions and organizations across nations. Thousand Oaks: Sage.

Hyde, M. K., and White, K. M. (2009). To be a donor or not to be? Applying an extended theory of planned behavior to predict posthumous organ donation intentions. Journal of Applied Social Psychology, 39, 880900.

Johnstone, L., and Lindh, C. (2018). The sustainability- age dilemma: A theory of (un) planned behaviour via influencers. Journal of Consumer Behaviour, 17(1).

Kashif, M., and De Run, E. C. (2015). Money donations intentions among Muslim donors: an extended theory of planned behavior model. International Journal of Nonprofit and Voluntary Sector Marketing, 20(1), 84-96.

Kashif, M., Sarifuddin, S., and Hassan, A. (2015). Charity donation: intentions and behaviour. Marketing Intelligence and Planning, 33(1), 90-102.

Koschate-Fischer, N., Stefan, I. V., and Hoyer, W. D. (2012). Willingness to Pay for Cause-Related Marketing: The Impact of Donation Amount and Moderating Effects. Journal of Marketing Research, 49(6), 910-927.

MacKenzie, S. B. (2003). The dangers of poor construct conceptualization. Journal of the Academy of Marketing Science, 31(3), 323-326.

Mannetti, L., Pierro, A., \& Livi, S. (2004). Recycling: Planned and self-expressive behaviour. Journal of environmental psychology, 24(2), 227-236.

Manstead, A. S. R. (2000). The role of moral norm in the attitude-behavior relation. In D. J. Terry \& M. A. Hogg (Eds.), Attitudes, behavior, and social context (pp. 11-30). Mahwah, NJ: Lawrence Erlbaum.

Matsumoto, D., Yoo, S. H., and Fontaine, J. (2008). Mapping expressive differences around the world the relationship between emotional display rules and individualism versus collectivism. Journal of crosscultural psychology, 39(1), 55-74.

Meijer, M. M. (2009). The effects of charity reputation on charitable giving. Corporate Reputation Review, 12(1), $33-42$. 
Middendorf, J., \& Kalish, A. (1996). The "change-up" in lectures. The National Teaching and Learning Forum, $5(2), 1-5$.

Nolan, J. M., Schultz, P. W., Cialdini, R. B., Goldstein, N. J., and Griskevicius, V. (2008). Normative social influence is under detected. Personality and social psychology bulletin, 34(7), 913-923.

Nunnally, J., and Bernstein, I. (1994). Psychometric Theory. 3rd edition. New York: McGraw-Hill.

Okun, M. A., and Sloane, E. S. (2002). Application of planned behavior theory to predicting volunteer enrolment by college students in a campus-based program. Social Behavior and Personality, 30, 243-250.

Peloza, J., and Hassay, D. (2007). A Typology of Charity Support Behaviors: Toward a Holistic View of Helping. Journal of Nonprofit and Public Sector Marketing, 17(1/2), 135-151

Peter, J. P. (1981). Construct validity: a review of basic issues and marketing practices. Journal of Marketing Research, 18(2), 133-145.

Ranganathan, S. K., and Henley, W. H. (2008). Determinants of charitable donation intentions: a structural equation model. International Journal of Nonprofit and Voluntary Sector Marketing, 13(1), 1-11.

Reitsma, J., Scheepers, P., \& Grotenhuis, M. T. (2006). Dimensions of individual religiosity and charity: crossnational effect differences in European countries?. Review of religious research, 347-362.

Reve, T. (1979). Construct validation in marketing: a comparison of methods in assessing the validity of the affective, conative, and cognitive components of attitudes. Advances in Consumer Research, 6, 288-294.

Rex, J., Lobo, A., \& Leckie, C. (2015). Evaluating the drivers of sustainable behavioral intentions: An application and extension of the theory of planned behavior. Journal of Nonprofit \& Public Sector Marketing, 27(3), 263-284.

Rivis, A., Sheeran, P., \& Armitage, C. J. (2009). Expanding the affective and normative components of the Theory of Planned Behavior: A meta- analysis of anticipated affect and moral norms. Journal of Applied Social Psychology,39(12), 2985-3019.

Sargeant, A. (2014). A retrospective-Charitable giving: Towards a model of donor behaviour. Social Business, 4(4), 293-323.

Sargeant, A., West, D. C., and Jay, E. (2007). The relational determinants of nonprofit website fundraising effectiveness: An exploratory study. Nonprofit Management and Leadership, 18(2), 141-156 
Sargeant, A., and Woodliffe, L. (2007). Building donor loyalty: The antecedents and role of commitment in the context of charity giving. Journal of Nonprofit and Public Sector Marketing, 18(2), 47-68.

Smith, J., and McSweeney, A. (2007). Charitable giving: The effectiveness of a revised theory of planned behaviour model in predicting donating intentions and behavior. Journal of Community and Applied Social Psychology, 17(5), 363-386.

Smith, P. B. (2015). Yes, Subjective Norms Are Important, but Let's Not Lose Sight of Cultural Differences. Journal of Cross-Cultural Psychology, Published online before print August 7, 2015, doi: $10.1177 / 0022022115599444$

Turcotte, M. (2015). Volunteering and charitable giving in Canada. Spotlight on Canadians: results from the General social survey. Retrieved from http://www.statcan.gc.ca/pub/89-652-x/89-652-x2015001-eng.pdf

van der Linden, S. (2011). Charitable Intent: A Moral or Social Construct? A Revised Theory of Planned Behavior Model. Current psychology, 30(4), 355-374.

Veldhuizen, I., Ferguson, E., de Kort, W., Donders, R., and Atsma, F. (2011). Exploring the dynamics of the theory of planned behavior in the context of blood donation: does donation experience make a difference?. Transfusion, 51(11), 2425-2437.

Warburton, J., \& Terry, D. J. (2000). Volunteer decision making by older people: A test of a revised theory of planned behavior. Basic and Applied Social Psychology, 22(3), 245-257.

Webb, D. J., Green, C. L., and Brashear, T. G. (2000). Development and validation of scales to measure attitudes influencing monetary donations to charitable organizations. Journal of the Academy of Marketing Science, 28(2), 299-309

Wymer, W., \& Alves, H. M. B. (2013). Scale development research in nonprofit management \& marketing: a content analysis and recommendation for best practices. International Review on Public and Nonprofit Marketing, 10(1), 65-86. 